\title{
Revisions to the therapeutic relationship: A qualitative inquiry into sexual abuse therapists' theories for practice as a mitigating factor in vicarious traumatisation
}

\author{
Margaret Pack
}

Margaret Pack, MA Applied in Social Work, PhD is a registered social worker and educator. Margaret's doctoral research: 'Sexual abuse counsellor's responses to stress and trauma: a social work perspective', was completed as a Bright Future Scholar at Victoria University in 2001.

\section{Abstract}

This article reports a qualitative study which explores sexual abuse counsellors' theories for practice and how they say they develop and use an array of theoretical approaches to support their well-being and clinical effectiveness over time. Half the sample of Accident Compensation Commission (ACC) registered therapists were social workers who subsequently trained in other professions such as counselling and psychotherapy. The findings suggest that social workers who engage with traumatic disclosures from their clients actively evolve strategies and resources that act to buffer the more negative effects of the work with sexual abuse survivors, which is a means of ameliorating vicarious traumatisation.

Whilst there was little theory specific to trauma work in the early 1980s when the research participants were practising, they developed a framework for their practice based in practice and personal experiences. These developed insights and reference to diverse strands of theory together constitute a framework for practice that assists the counsellors' in their understanding of their clients, the dynamics of the therapeutic relationship, organisational constraints on funding that surround their work, and their own self care. The theoretical frameworks that the participants preferred to use derive from social justice principles, feminist, narrative theories and the 'New Trauma Therapy' (Coffey 1998). Recommendations for clinician self care in dealing with traumatic disclosures with reference to a range of theoretical approaches are suggested.

\section{Introduction}

The recent media reports of changes to processes for ACC funding for sexual abuse has highlighted the important role publicly funded therapy has for the survivors of violence to regain their quality of life (Kay, 2009; Hayward, 2009). These reports in the media indicate the importance the issue has in the New Zealand public's consciousness.

The difference in philosophy between the statutory funding requirements and the way practitioners who contract to provide this service, say that they work in practice with their clients, is also highlighted by these debates. The new ACC requirement recently announced in which mental injury needs to be established medically at more frequent junctures during the therapy, often involving psychiatric and medical assessment and re-assessment, has been questioned on ethical grounds by the registered counsellors as a group (Hayward, 2009; 
Kay, 2009). These additional reporting and assessment requirements have been described as 'unethical' due to the restrictions funding conditions impose on the therapist and therapeutic relationships with clients (Kay, 2009; Hayward, 2009).

In research I conducted in 2002 with ACC-registered therapists, a theme in the interviews was the lack of recognition of the importance of relationship in the way the funding arrangements worked in practice. For the counsellors interviewed about vicarious traumatisation, they described the part of their job they found the most 'traumatising' as managing the statutory reporting and assessment requirements alongside the need to maintain the therapeutic relationship. I developed a model of vicarious traumatisation that included the organisational or structural component, to explain this experience described by the counsellors I interviewed. I found that through reference to theory and practice wisdom, the participants also found ways of working creatively within the organisational and funding constrains, however. This paper focuses on the theoretical frameworks that the participants in the study said that they drew upon which acted as a protective factor promoting vicarious resilience in their practice with sexual abuse survivors.

The negative orientation of the vicarious traumatisation framework has recently been challenged as sexual abuse counsellors over time have been discovered to evolve ways of being that are protective of their personal well-being and professional effectiveness (Gelso and Hayes, 2007; Steed \& Downing, 1998). In this article, I explore the historical background and context to the theoretical eclecticism described by the participants interviewed for research I undertook as my doctorate in social work. The findings suggest that the practitioners' reference to theory is both a resource and protective factor which is drawn upon to support the day-to-day work of sexual abuse therapy. This paper therefore draws from a larger study of counsellor stress and trauma which triangulated the responses of the counsellors with the perceptions of their nominated family, friends and colleagues (Pack, 2004, and Pack, forthcoming).

\section{Key definitions}

Vicarious traumatisation is a process that occurs when a worker's sense of self and world view is negatively transformed through empathetic engagement with traumatic disclosures from clients (Pearlman \& Saakvitne, 1995). The effects are considered to be cumulative, permanent and irreversible if unattended (Pearlman \& Saakvitne, 1995). The basic premise of 'cognitive self-development theory', underpinning the concept of vicarious traumatisation, is that individuals 'construct their own personal realities through the development of complex cognitive structures which are used to interpret events' (McCann \& Pearlman, 1990, p. 137). Self-constructivist development theory on which the notion of vicarious traumatisation is prefaced, explores the effects of exposure to trauma on five fundamental psychological needs which relate to the dimensions of 'safety, dependency, trust, esteem and intimacy' (McCann \& Pearlman, 1990, p. 137). In later writings, 'frame of reference', 'independence' and 'imagery systems of memory' were added to this list (Pearlman \& Saakvitne, 1995; Pearlman \& MacIan, 1995; Pearlman et al, 1996). The hypothesis of constructivist self-development theory is that the therapists' cognitive constructs relating to these 'fundamental needs' will be altered, often permanently, by continued involvement with traumatic material. These ideas are congruent with those of Dutton (1992), who discusses some of the common changes in belief that therapists routinely encounter when working with domestic violence 
survivors, and Moulden \& Firestone (2007) discuss in relation to the impact of work with sexual offenders.

\section{Background: The context of therapy for sexual abuse survivors in Aotearoa}

In New Zealand sexual abuse therapy is publicly funded as survivors of sexual abuse trauma are covered under the ACC which provides funded psychotherapy to claimants as the main means of 'recovery'. Currently there are in excess of 12,000 active sensitive claims, 3,500 being lodged in 2006. The cost of sensitive claims amounted to more than $\$ 32$ million in 2006 (ACC Treatment Providers' Newsletter, 2007). Once a sensitive claim is accepted, claimants are able to obtain counselling as one of the main methods of recovery from trauma. An increasing range of counselling professionals, including clinical psychologists, psychotherapists and social workers, have chosen to register to provide this specialised service.

The public funding of therapy for sexual abuse survivors represented to the counsellorparticipants a double edged sword. Reporting requirements of ACC were considered by the research participants interviewed to hold the potential for episodic disruptions in the therapeutic relationship they held with their clients which they constructed as a collaborative endeavour by witnessing their clients' narratives. These reporting requirements were found to be the major challenge in working within the field from the counselling participants' perspectives as it meant that they were required to move out of a relational mode of being with the client to reporting the details of their client's abuse and biography to determine eligibility for ongoing funding of therapy. Sometimes this meant that they needed to delineate the part of the abuse that was covered by the sensitive claim, so that a specific event could be actively worked with to secure eligibility for ongoing public funding.

The requirement for counsellors to determine 'mental injury' to establish the ongoing need for funding was seen as pathologising the client. More recently psychotherapists have criticised in the media ACC's requirement of periodic referral to a psychiatrist to establish mental illness arising from the original event for which the claim has been accepted to secure ongoing funding for treatment (Hayward, 2009).

\section{Literature review}

More recent studies have discovered that the presence of protective factors operate to mitigate the negative impact of the work with trauma on the practitioner (Gelso \& Hayes, 2007). These factors include the counsellor's ability to actively access and use social supports, deal with organisational stressors present in their workplaces, and moderate their own empathy to regulate emotional responsiveness (Badger et al, 2008). Strategies including the use of collegial and personal support, clinical supervision and personal therapy have all been discussed in relation to what promotes worker resilience in the field of trauma recovery from a social work perspective (Pack, 2004; Badger, Royse, \& Craig, 2008). Knowledge of theoretical approaches facilitate awareness, understanding and integration of the distressing countertransference responses that are evoked in the work with trauma survivors, and provides a further means of making meaning from experience for clinicians (Gelso \& Hayes, 2007). Personal insight, conceptualising skills, empathy, self integration and anxiety management have been found to be relevant to the well-being of the practitioner who engages with sexual abuse disclosures (Gelso \& Hayes, 2007, p. 102). Such factors promote 'vicarious resilience' (Gelso \& Hayes, 2007) which enables the practitioner to 'bounce back' from the usual challenges of trauma- 
related helping. Therefore, the process by which these conceptualising skills with reference to theory is evoked in the work with sexual abuse survivors was one of the aims chosen for the research into sexual abuse therapists' experiences of the work.

\section{Aims of the study}

My aim as a social work researcher was to elicit 'thick description' (Geertz, 1975) on the topic of vicarious traumatisation which appeared to be missing in the tradition of research on vicarious traumatisation which originally was developed from survey research by clinical psychologists (McCann \& Pearlman, 1990; Pearlman \& Saakvitne, 1995). Therefore, I aimed to explore sexual abuse counsellors' views of the vicarious traumatisation literature in the New Zealand context by researching the counsellors' viewpoints and practice narratives in response to the original vicarious traumatisation framework (McCann \& Pearlman, 1990).

\section{Methodological approach}

A qualitative, participative design was chosen to research the question of whether vicarious traumatisation was an issue from the individual counsellor's experience of the work. Secondly the intention was to discover how the nature of the work with traumatic disclosures had impacted on the family members of the counsellors (Pack, 2004 and Pack, forthcoming). Due to the sensitive nature of the topic and the need to elicit in-depth discussion from a narrative perspective, a semi-structured topic guide was developed in liaison with a focus group of currently practising ACC psychotherapists to pretest the relevance of the methodological approach and methods chosen. At the data analysis stage, early themes were presented to the group for discussion and feedback in a way suggested in feminist and participative research methodologies (Reason, 1998; Reinharz, 1992).

\section{The counsellor-participants}

The participants in this research (hereafter referred to as the counsellor-participants) were selected using a systematic sample from ACC's Register of Approved Counsellors. Therefore, a representative sample of a range of professional groupings within the register (social workers, psychotherapists, counsellors and psychologists) was sought by selecting individuals from several different professional associations. It was discovered once the fieldwork commenced that half the sample were social workers by their first training, later moving through further training to more specialised psychotherapy and counselling roles. This career trajectory and background is indicative of many professionals who register to provide ACC sexual abuse therapy in New Zealand.

\section{Methods}

Twenty-two counsellor-participants were interviewed individually in total, using qualitative research design and methods. Ethical approval from Victoria University was obtained before the project commenced. The data from in-depth interviews was transcribed and analysed thematically, guided by a focus group who acted as consultants throughout the project to verify and analyse emerging themes. 


\section{Data analysis}

Similarities and differences within the counsellor narratives were analysed using thematic analysis and 'pattern-matching' (Yin, 1985) in which each interview transcript was analysed for internal consistency and themes. These themes were identified as recurring patterns within the transcripts and then discussed with the focus group to add a further layer of verification. The counsellor-participants chose their own pseudonyms to represent their individual contributions.

The relevance of the original vicarious traumatisation framework (McCann \& Pearlman, 1990) was used to analyse the themes across the counsellor-participants as a group alongside the notion of protective factors leading to vicarious resilience, drawn from the risk and resilience literature (Steed \& Downing, 1998).

Thematic analysis to determine patterns in the data, therefore, guided the interpretation of findings together with reference to a focus group (Reason, 1982). To analyze the emerging findings and to avoid the researcher's frame of reference being the only means of verification, a focus group of five currently practicing sexual abuse counselors were involved throughout the project by the organization of monthly meetings. Early themes were discussed for relevancy and the group's comments were incorporated in the data analysis over the duration of the study in a way that is recommended in participative research approaches (Reason, 1988).

\section{Findings: A 'baptism by fire'}

The current research participants, who were trailblazers in working with those sexually abused in the New Zealand context, referred to the experimental nature of their early work. A consultant to the present study, Ellen, became aware of the prevalence of sexual abuse through her involvement as a media personality in a talkback radio and television programmes where viewers wrote and talked to her on air. Later Ellen trained in psychology and became a psychotherapist. This narrative of Ellen's personal journey, illustrates the eclecticism of roles and approaches that were evoked by the historical times in which she was working and the dynamic tension between her early training and later on-the-job experiences. For Ellen and the other counsellor-participants, these transformations in outlook and changing times necessitate a reformulation of who one is, what one does and how one engages with clients:

\footnotetext{
One important lesson that I learned out of this was that one could invite a person whom I was corresponding with, to write in as much detail as they felt safe to or able to do. To either write in detail or to draw what the trauma was or what the pictures were that stayed in their mind. Flashbacks really. And by correspondence we were actually able to work through those. I find it quite extraordinary now looking back on that because I didn't even know that post traumatic stress disorder existed. I certainly didn't know what the name would be but we were actually working with it then. Now by 1986 I was probably dealing with hundreds of letters, many of them about sexual abuse, incest and from guys in prison who were able to talk about their own abuse but not prepared to talk about it to authorities, so we had quite a lot of experience then in talking to perpetrators by letter.
}

The lack of published work and theory to underpin the early efforts of counsellors was a theme for the counsellors interviewed. 'The Courage to Heal' (Davis, 1992) a self help 
manual for sexual abuse survivors was referred to guide the work. This lack of a coherent theory about trauma and the aftermath set Ellen and the other counsellor-participants in a search for theories and further training that could support their practice. As Ellen continues to explain:

Even later I became a co-host and dealt with sexual abuse, incest and so on, on air. The issues were widespread; they crossed socio-economic barriers. There was just a very wide exposure to abuse issues throughout the country. However, by 1991, now trained as a psychotherapist, I decided that I wanted to work more in-depth with abused and traumatised clients. And knew that I was going to be looking at long-term work. And this still continues. In that time I had worked with clients who have been ritually abused as children and DID [dissociative identity disorder] clients and it's been, through working with them, I think, that most of my internal changing would have taken place.

\section{Theoretical underpinnings to practice}

'The New Trauma Therapy' (NTT) as proposed by Coffey (1998) and epitomised in the writings of Herman (1992), Briere (1996), Courtois (1997) and Dalenberg (2000), among others, represents the eclecticism that the counsellor-participants discussed as being central to their work with sexual abuse survivors. Theories encompassed by NTT were discussed as guiding their own healing from traumatic events and recovery from vicarious traumatisation. NTT is derived from a range of theories and sources. It re-conceptualises the therapeutic relationship in ways that assist the healing processes of survivors of trauma. It ameliorates the counsellors' own experiences of trauma, both their own and vicariously experienced. As Coffey (1998), a writer who has researched trauma therapists and their work with survivors, suggests NTT is a synthesis of Freud and newer theorists. Coffey (1998, p. 163) refers to the research of trauma theorists Kluft and Gartrell to suggest the potential pitfalls of abandoning established psychotherapeutic practice and approaches when dealing with traumatised clients. Coffey (1998, p.163) concludes after interviewing sexual abuse survivors and trauma theorists that: 'therapists who toss aside all psychotherapeutic tradition may also unwittingly and perilously toss aside its protections, forcing themselves to blaze unnecessarily chancy paths through precarious jungles'.

The research participants often disliked the need to categorise clients using systems of classification such as the DSM IV-TR, preferring to use approaches drawn from NTT in their work with traumatised clients. They viewed these approaches as complementing the traditional psychodynamic models with ideas closer to their own theories and ways of thinking. Herman (1992) and other theorists within NTT referred to the historical and social contexts in which people experience trauma. This attention to context and wider social systems was missing in more individual-focused, medically orientated approaches. This refocusing of attention onto context was itself a product of the historical times in which Herman and the new trauma therapists were witnesses to a culture of disbelief about abuse. Therapy as a political act to challenging the disbelief about the prevalence of abuse that exists in society has provided important framing to the disclosures from survivors (Herman, 1992).

In a similar way, the counsellor-participants described responding to the disbelief they encountered within the wider community about the prevalence of sexual abuse in the New Zealand context. They conceptualised their roles as therapists as enabling survivors to regain 
their voice and their narratives. Within such reclaiming, there is a potential for returning to principles of social justice in approaching sexual abuse and recovery.

Jill, one of the counsellor-participants in the research, for example, expressed reservations about her early training to be a psychotherapist. She found her personal experiences in various experiential, psychodynamic therapy contexts did not fit with her wider analysis of class, gender and oppression. Later, she trained as a social worker and, in being introduced to the writings of Freire (1970), found an alternative model that better fitted with her personal philosophy, as a 'working class' woman. She elaborated her ideas into the concept of therapy as liberation from social/personal oppression. She recalled coming across such theories as 'a homecoming' after years of training in various psychoanalytic/ psychodynamic approaches:

When I went to do social work training, that was a real homecoming for me and just really reading Freire was the thing, and after that I always felt that I had this touchstone in a way. Because there wasn't really even any feminist counselling material out at that time, that wasn't quite psychodynamic. But I like that idea of Freire's, about being in solidarity with people, as they changed their perception of themselves, as they began to appreciate themselves in this way, and so I always just used that and I still revert to that. And I noticed in a book that's just been published by Freire's wife, after his death, about his thinking on getting on with the oppressed, which was the first book I read, and the first one he wrote, where he was saying that, in fact, that was 'therapy'. What he was talking about was not just liberation theory, it was therapy. And I began to think about therapy as liberation and that was what we were doing really, and that a person needed to be liberated socially in terms of their personal safety but also that your mind has to be liberated as well. And so that's how I've always thought about what I do and still think about it in this way.

Throughout their training, Mary and Beth, another two of the counsellor-participants in the research, described integrating structural and individual perspectives in their work. Both focus on their experiences as women and their experiences in personal therapy as informing how they work with their clients. Being a survivor of abuse or not may not be the central issue here. As Mary suggests, women are all, in a sense, survivors of dominance by patriarchal institutions and relationships. Both Beth and Mary find the 'expert' role as ill fitting their respective approaches with clients with whom they prefer to be in 'partnership' (Beth) or in 'solidarity' (Jill). Their respective visions of the world revolve around working with the wider systems, which influence people's lives. These ideas encompass notions of difference and diversity. Sexual abuse is viewed as being one example of the many sources of oppression in society. The role of power in social relationships, including the therapeutic relationship becomes the primary focus of attention. Such an analysis is not only useful as a tool for personal transformation. It is also useful as the basis for a critical appraisal of one's own practice and the broader context in which therapy takes place. As Mary explains:

What I am enjoying now about where some of the narrative writers and therapists have got to is the both/and, rather than going into dualisms. That the importance of acknowledging - and I need to define problems clearly as well as acknowledging pain - and then offering hope as well. And that comes back full circle with clients into therapy which is really hearing and letting the client know that you are really hearing. I was quite influenced by a statement that, I don't know who made it, but I first heard it from another therapist. It was something like: 'the core of counselling is something about not moving somebody on but encouraging the person to be where they are when they themselves are able to be there'. 


\section{Discussion}

The eclectic and holistic nature of theoretical approaches they espoused enabled the counsellor-participants to keep pace with the transformations they were experiencing in themselves and in relation to their work. Their critical appraisals of earlier training, experiences and personal and professional growth necessitated revisions to their initial conceptualisation of the therapeutic relationship. NTT conceptualised the therapeutic relationship in ways that were more compatible with these revisions as the concept of 'witnessing' (Herman, 1992) enabled them to adopt a narrative and social justice paradigm in their work alongside other psychodynamically orientated theories. This sense of integrating a diverse range of theories in their practice with sexual abuse survivors was described as a resource in the participants' work, enabling them to remain feeling connected to their value base for practice, which is an ameliorating factor in vicarious traumatisation (Pack, 2004).

\section{Implications for practice}

The changes to current ACC Sensitive Claims processes focus on the assessment/ review and evaluation processes to establish the need for treatment on the basis of mental injury. Counsellors in this study found these processes before the recent proposed changes to be the most challenging part of the role. Being in an uninterrupted relationship with their clients enabled the counsellor-participants to stay connected with their diverse sources of theory, which include an awareness of vicarious traumatisation and a political analysis of why abuse occurs in society. On the basis of this awareness, counsellors had developed and internalised knowledge of how to manage their own trauma and stress effectively, which if unaddressed can accumulate and result in vicarious traumatisation over time. The findings suggest that there needs to be realignment of the philosophies of the organisations involved in sexual abuse work toward an approach consistent with the practice of counsellors, i.e. what counsellors actually do in practice with their clients. Based in this research, a synthesis of narrative, anti-oppressive and strengths-based frameworks offers a possible meeting place for organisations and workers to engage in a dialogue on these issues about the assessment and evaluation processes needed to apply for continued funding of therapy.

At a time when counselling professionals are under increasing pressure and scrutiny to be effective in producing measurable outcomes, the context in which sexual abuse counselling occurs is defined by its unpredictability. ACC counselling largely defies managerial attempts at control and integration, despite vigorous attempts to the contrary. Paradoxically, larger numbers of survivors are presenting to helping services throughout New Zealand than previously. Services to sexual abuse survivors in the climate of budgetary control and tightening of the public purse strings are increasingly producing diverse and fragmented services which remain largely uncoordinated. In this climate, it becomes difficult for professions such as social work, counsellors and psychotherapists to enact their professions' values or goals. As Fook (2000) found in a five-year longitudinal study of social workers, as representatives of the 'caring professions' founded on principles of social justice, it becomes increasingly problematic in the managerial climate of statutory organisations for social workers to know how to begin to practise to embody these principles.

\section{Conclusion}

Trauma counsellors are aware that in turning a blind eye to the stories of oppression they hear daily, they risk avoiding the issues of their own vulnerability and the possibility of travelling 
the same path as survivors to becoming vicariously traumatised. In this sense, therapy is a highly personal and politicised activity that aims to redress the grievances of those whose trust has been deeply betrayed. To locate these abuses as residing in the individual, is a re-enactment of the blaming/denial dynamics of the original abuse. For some therapists uncovering the collective injustices that exist is an unexpected outcome of their witnessing of individual narratives of oppression. Conceptualised this way, the need for emancipatory modes of practice unfolds with the telling and re-telling of the individual narrative and the therapists' awareness of the connecting themes within these narratives.

The expectation of practice from an organisational perspective is one based in scientific knowledge that draws cause-and-effect relationships. The presenting problems or issues seem to automatically lead to diagnosis or formulation which then assumes 'treatment' and ultimately, 'cure'. Such a model of causality fits uneasily with dealing with survivors of trauma from the perspective of the counsellor-participants. This view distances the worker into a role of diagnostic expert. Organisational discourses which are authored within 'residual' or 'maintenance' approaches (Adams, Dominelli, \& Payne, 2009, pp. 209-214) need to acknowledge and facilitate the ways in which counsellors and clients relate.

For the therapists who engage with clients recovering from the aftermath of trauma, there is an urgent need for developing frameworks for practice that combine knowledge about trauma with the principles of anti-oppressive and emancipatory approaches. This theme arising from my research resonates with the feminist and anti-oppressive range of theoretical approaches to practice (Adams et al., 2009, pp. 209-214).

As a result of repeating the development of the therapeutic relationship with each new client, the counsellor-participants drew from an eclectic mix of theories to inform their practice. Given the gross transgressions of physical boundaries that have taken place for the trauma survivor, the central dilemma for the therapist is: 'how can I supply what the client needs without replicating what happened before?' Secondly, 'if the occurrence of sexual abuse is indicative of skewed relationships in which power is misused and the survivor is denied her own subjectivity, how do I assist in the retrieval of the client's own voice?' The counsellor-participants' own training provided few constructive answers to these dilemmas. Feminist approaches and theories that encompass principles of social justice and social systems, were found more useful. Frameworks that integrate the various strands of these theories, including NTT, the counsellor-participants found to be the most relevant. Within NTT the therapeutic relationship creates the climate in which clients can re-discover their own innate resilience and, through this awareness, to enable them to carry this knowledge into action in their everyday lives. The findings of my research suggest that there needs to be realignment in the philosophies of the funding organisations involved in sexual abuse work toward an approach consistent with these aims and with the practice of counsellors.

\section{References}

ACC Register of Approved Counsellors, (1998).

ACC Sensitive Claims' Treatment Providers Newsletter, (2007).

Adams, R., Dominelli, L., \& Payne, M. (2009). Critical practice in social work. Basingstoke, England: Palgrave Mcmillan.

Badger, K., Royse, D., \& Craig, C. (2008). Hospital social workers and indirect trauma exposure: An exploratory study of contributing factors. Health and Social Work, 33(1), 63-71.

Briere, J. (1996). Therapy for adults molested as children: Beyond survival. New York: Springer Publishing. 
Coffey, R. (1998). Unspeakable truths and happy endings: Human cruelty and the New Trauma Therapy. New York: Sidran Press.

Courtois, C. A. (1988). Healing the incest wound: Adult survivors in therapy. New York: W.W. Norton.

Courtois, C. A. (1997). Healing the incest wound: A treatment update with attention to recovered memory issues. American Journal of Psychotherapy, 51(4), 464-497.

Cunningham, M. (2003). Impact of trauma work on social work clinicians: Empirical findings. Social Work, 48(4), 451-59.

Dalenberg, C. (2000). Countertransference and the treatment of trauma. La Jolla Calf: American Psychological Association.

Davis, L., \& Bass, E. (1992). The courage to heal (3rd ed.). New York: Harper Perennial.

Dutton, M. A. (1992). Empowering and healing the battered woman: A model for assessment and intervention. New York: Springer Publishing.

Fook, J. (2002). Social work: Critical theory and practice. London: Sage.

Freire, P. (1970). Pedagogy of the oppressed. (Myra Bergman Ramos, Trans.). New York: Seabury.

Geertz, C. (1975). The interpretation of cultures: Selected essays. London: Basic Books.

Gelso, C. J., \& Hayes, J. A. (2007). Countertransference and the therapist's inner experience: Perils and possibilities. New Jersey: Lawrence Erlbaum Associates.

Hayward, J. (2009, October 17). Letter to the Editor. Listener.

Herman, J. (1992). Trauma and recovery. New York, Basic Books.

Kay, M. (2009, October 28). Review of sex abuse compo. Dominion Post.

McCann, I. L., \& Pearlman, L. A. (1990). Vicarious traumatisation: A framework for understanding the psychological effects of working with victims. Journal of Traumatic Stress, 3(1), 131-149.

Moulden, H. M., \& Firestone, P. (2007). Vicarious traumatisation: The impact on therapists who work with sexual offenders. Trauma Violence and Abuse, 8(1), 67-83.

Pack, M. J. (2004). Sexual abuse counsellors' responses to stress and trauma: A social work perspective. New Zealand Journal of Counselling, 25(2), 1-17.

Pack, M. J. (Forthcoming) Transformation in progress: The effects of trauma on the significant others of sexual abuse therapists. Qualitative Social Work: Research and Practice.

Pearlman L. A., \& MacIan, P. S. (1995). Vicarious traumatisation: An empirical study of the effects of trauma work on trauma therapists. Professional Psychology: Research and Practice 26, 558-565.

Pearlman, L. A., \& Saakvitne, K. W. (1995). Trauma and the therapist: Countertransference and vicarious traumatisation in psychotherapy with incest survivors. New York: Norton.

Pearlman, L. A., Saakvitne, K.W., \& Staff of the Traumatic Stress Institute. (1996). Transforming the pain: A workbook on vicarious traumatisation for helping professionals who work with traumatised clients. New York: Norton.

Reason, P. (Ed.). (1988). Human inquiry in action: Developments in new paradigm research. London: Sage Publications.

Reinharz, S. (1992). Feminist methods in social research. New York: Oxford University Press.

Steed, L. G., \& Downing, R. (1998). Vicarious traumatisation amongst psychologists and professional counsellors working in the field of sexual abuse/assault. The Australasian Journal of Disaster and Trauma Studies. Retrieved on 1 May 2009 at http: / / www.massey.ac.nz/ trauma/issues/1998-2/ steed.htm

Yin, R. (1985). Case study research. New York: Sage Publications. 